\title{
Local and regional richness and rarity of leaf-litter ants: An overview from spacial scale in neotropical region
}

\author{
Manoel Fernando Demétrio ${ }^{1,2}$, Rogério Silvestre ${ }^{1,2}$ \\ ${ }^{1}$ Programa de Pós Graduação em Entomologia e Conservação da Biodiversidade, Universidade Federal da Grande Dourados, Dourados, \\ Mato Grosso do Sul, Brazil; ${ }^{*}$ Corresponding Author: mfdemetrio@gmail.com \\ ${ }^{2}$ Laboratório de Ecologia de Hymenoptera HECOLAB, Faculdade de Ciências Biológicas e Ambientais-UFGD, Cidade Universitária, \\ Dourados, Mato Grosso do Sul, Brazil
}

Received 22 April 2013; revised 25 May 2013; accepted 2 June 2013

Copyright (C) 2013 Manoel Fernando Demétrio, Rogério Silvestre. This is an open access article distributed under the Creative Commons Attribution License, which permits unrestricted use, distribution, and reproduction in any medium, provided the original work is properly cited.

\begin{abstract}
An unusual approach about richness and rarity of leaf-litter ant species is presented here from a dry forest reminiscent in Pantanal province (Chacoan subregion) suggesting the boundaries that defining local and regional scales for this particular ant community. We analysed the frequency of distribution of 170 ant species collected on 262 Winkler's samples along Serra da Bodoquena National Park, Mato Grosso do Sul state, Brazil and described some ecological mechanisms that made the species richness estimates be highly influenced by species with low frequencies of records in an extent regional of a pristine dry forest. Bayesian inference was conducted to provide if the probability of latitudinal gradient was correlated with the species richness to define alpha diversity.
\end{abstract}

Keywords: Alpha Diversity; Formicidae; Rarity Patterns; Regional Scale

\section{INTRODUCTION}

Why this distribution of species abundances is so regularly observed among different taxonomic sets in geographically diverse systems is a question that has received considerable theoretical and empirical investigation [1-5].

There is an abiding interest in the number of species in local communities, because species are fundamental biodiversity units $[1,6]$. A major research agenda in ecology is to explain the geographic patterns of the species rich- ness [7]. Many studies address the latitudinal change in species richness and why there are so many species in the tropics [8]. Others examine the species distribution changes related with elevation [9-11], asking whether and why there is a mid-elevation peak in diversity. Conservation biologists examine whether species richness changes with land use or landscape fragmentation, and whether richness changes over time [12]. What challenges our ability to interpret natural phenomena is that when we investigate what apparently is not correlated to any of the physical, climatic and taxocenotic characteristics involving the patterns of species distribution? In which situations and how often this lack of standards can occur on a local and regional scale?

Ants and other invertebrate organisms should be included in biodiversity studies because of their high diversity and rapid response to environmental changes [13, 14]. When choosing invertebrate taxa to survey, the relative merits of different taxa are often discussed [15], but there are several reasons for choosing ants to investigate biodiversity patterns [16]. In most terrestrial ecosystems, ants are a conspicuous presence and they are among the most commonly studied terrestrial invertebrates. They are mostly scavengers and predators, and they have large impacts on soil formation, seed predation/dispersal, and in the invertebrate community structure $[17,18]$. Therefore, ants are particularly good candidates for monitoring community changes that may occur due to climate change or habitat fragmentation [19].

Rarity pattern of leaf-litter ants is an important research topic in myrmecology, because it has relevance to the biogeographical and ecological research. The assessment of leaf-litter ants community reveals a high structural complexity on micro-scales and represents the 
next step on biodiversity studies. A challenging task is to understand patterns of species richness, abundance and rarity at larger spatial scales, extending to the entire geographic range of species [20,21].

The high number of species that co-occur presupposes the availability of nests and a spatiotemporal constancy of resources [22]. In the Leaf-litter strata, the ant species richness is high, with up to 30 species co-occurring in one square meter [13,23-25]. The assessment of this situation could promote a better comprehension about the ant species incidence in local and regional scale, and could answer some questions about the permanence of rare species on forest sites, and establishing indicative of what's possible environmental filters and/or exclusion competitive processes can prevail in model observed.

The species rarity of hyperdiverse taxon such as Formicidae could be an excellent tool for investigating forests primaries environments which corroborate for understanding ecological patterns like rare species and environmental heterogeneity [21]. Regional patterns of species richness in nature which occur over a variety of spatiotemporal scales are sometimes referred to as general laws of ecology [26,27]. Numerous ecological patterns exist, although many generalizations have been accepted without substantial evidence [28]. These general ecology laws are changing with the chaotic vision, and many traditional metrics of diversity need revision. A simple characterization of ant diversity in an uninsulated unit area can be more complicated than we think. The general assumption that habitat complexity is positively associated with the diversity and rarity of its constituent fauna may not be strongly supported across scale, taxa and sys- tems being investigated to historical and contemporaneous process [29].

In this paper, we purpose an unusual discussion about richness and rarity of ant species on the leaf-litter strata in a dry forests reminiscent in mid-western of Brazil, in the Pantanal province inserted on the Chacoan sub-region [30], and how we can infer the boundaries demarcating local and regional scales, testing by Bayesian methods if the species richness is autocorrelated with latitude and longitude profile to local from regional scale.

\section{MATERIAL AND METHODS}

We'd been surveying on the Serra da Bodoquena National Park, localized on mid-western region of Brazil. The Bodoquena's mountain range National Park, with 77.232 ha, frames on Cerrado-Pantanal biodiversity corridor; it is inserted on core area of Atlantic Forest biosphere reserve. The area is an environmental planning unit being a watershed which supplies the hydrological basin of western Brazil [31].

We surveyed on 10 localities occurred from September 2005 to February 2008, totalizing 262 leaf-litter samples along the one continuum block of Decidual Forest. The geographical coordinates of the sites was as following: Site 01-2 ${ }^{\circ} 27^{\prime} 55^{\prime \prime} \mathrm{S}, 56^{\circ} 48^{\prime} 34.3^{\prime \prime} \mathrm{W}$; 02-2 $1^{\circ} 30^{\prime} 58.7^{\prime \prime S}$, $56^{\circ} 57^{\prime} 59.1^{\prime \prime} \mathrm{W} ; 03-21^{\circ} 07^{\prime} 14.7^{\prime \prime} \mathrm{S}, 56^{\circ} 43^{\prime} 08.2^{\prime \prime} \mathrm{W} ; \mathbf{0 4}$ $20^{\circ} 46^{\prime} 56.2^{\prime \prime} \mathrm{S}, 56^{\circ} 44^{\prime} 31.2^{\prime \prime} \mathrm{W} ; 05-21^{\circ} 17^{\prime} 09.8^{\prime \prime} \mathrm{S}$,

$56^{\circ} 41^{\prime} 45.5^{\prime \prime} \mathrm{W} ; 06-20^{\circ} 42^{\prime} 07.0^{\prime \prime} \mathrm{S}, 56^{\circ} 52^{\prime} 47.7^{\prime \prime} \mathrm{W} ; \mathbf{0 7}$ $20^{\circ} 32^{\prime} 41.48^{\prime \prime S}, 56^{\circ} 54^{\prime} 44.66^{\prime \prime} \mathrm{W}$; 08-2050’26.16"S,

$56^{\circ} 47^{\prime} 31.85^{\prime \prime} \mathrm{W} ; 09-20^{\circ} 45^{\prime} 53,6^{\prime \prime} \mathrm{S}, 56^{\circ} 44^{\prime} 53.11^{\prime \prime} \mathrm{W} ; \mathbf{1 0}$ $21^{\circ} 25^{\prime} 39.24^{\prime \prime} \mathrm{S}, 56^{\circ} 45^{\prime} 48.90^{\prime \prime} \mathrm{W}$ (Figure 1).
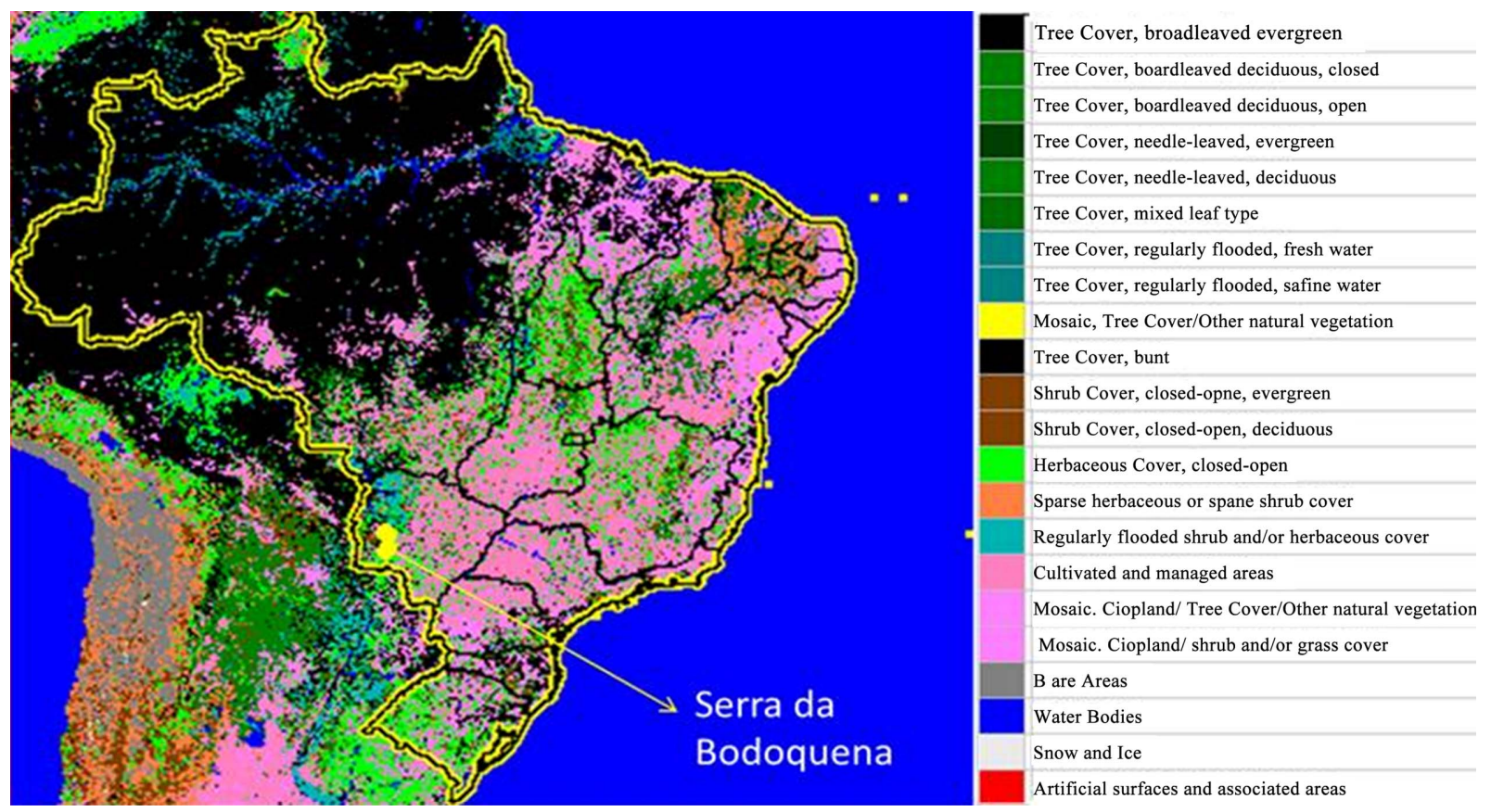

Figure 1. Investigated area in mid-western Brazil, showing land cover and Bodoquena's mountain range National Park. 
The leaf-litter sampling was realized following Ants of the Leaf Litter protocol [32]. For each sample unit was extracted one square meter of leaf-litter in Winkler's apparatuses covering one transect with $10.000 \mathrm{~m}^{2}$. The sampling site was choosing by selective form inside of each point, seeking the best micro-habitats for the leaflitter extraction on forest, in general, near to biggest trees. In each sampling point was extracted material until the superficial soil layer. The sifted volume with up $2 \mathrm{~kg}$ was transfer to a collector bag. In the field laboratory this material was extracted with mini-Winkler apparatuses for 24 hours, and after this period, the specimens were put in Eppendorfs pots. In the Hymenoptera Ecology Laboratory (HECOLAB-UFGD) individuals were kept in entomological pins on triangles of plastic. The voucher specimens were deposited on Biodiversity Museum of Universidade Federal da Grande Dourados (UFGD), Mato Grosso do Sul State, Brazil.

\section{Data Analyses}

We perform our analyses for calculate ICE, Singletons (uniques) and Doubletons (duplicates) utilizing EstimateS statistic package, 8.0 version [33]. ICE belongs to a class of non parametric estimators of species richness that are based on the number of rare species found in samples and assumes that the number of rare species decreases with increased sampling [34,35].

The data was available utilizing the species record's frequency at the each sampling plot because is the better parameter for social insects [36]. We utilized a scale of classes of frequency $(\mathrm{F})$ of records to $1 \%-100 \%$.

The correlation analysis was realized utilizing the datasets (ICE, Sobs, Singletons and Doubletons) and computed on Systat 12 software [37]. We utilized the Pearson Correlation index. For test if the local geographical coordinates has relationship with species richness we utilized the WinBUGS software for Bayesian models, version 3.1.2 [38]. The model is on the Appen$\operatorname{dix} 01$.

\section{RESULTS}

We recorded 170 species of leaf-litter ants on dry forests inside the Bodoquena's mountain range National Park. For the complete species list see [21]. A total of 37 species were recorded just once (singletons) and 17 species recorded twice (doubletons). The total number of singletons and doubletons was representative reflecting about $32 \%$ of all ants species collected in all field campaigns. We observed an inverse relation between the number of most frequent species and the number of rare species, or else, species group recorded in $100 \%$ of samples was lesser than others groups recorded once and twice times (Figure 2).
The Pearson's correlation analysis (Table 1, Figure 3) indicated a strong positive correlation between the number of species observed (Sobs) with singletons $(\mathrm{R}=$ $0.999)$ and doubletons $(\mathrm{R}=0.881)$ and a moderate nega-

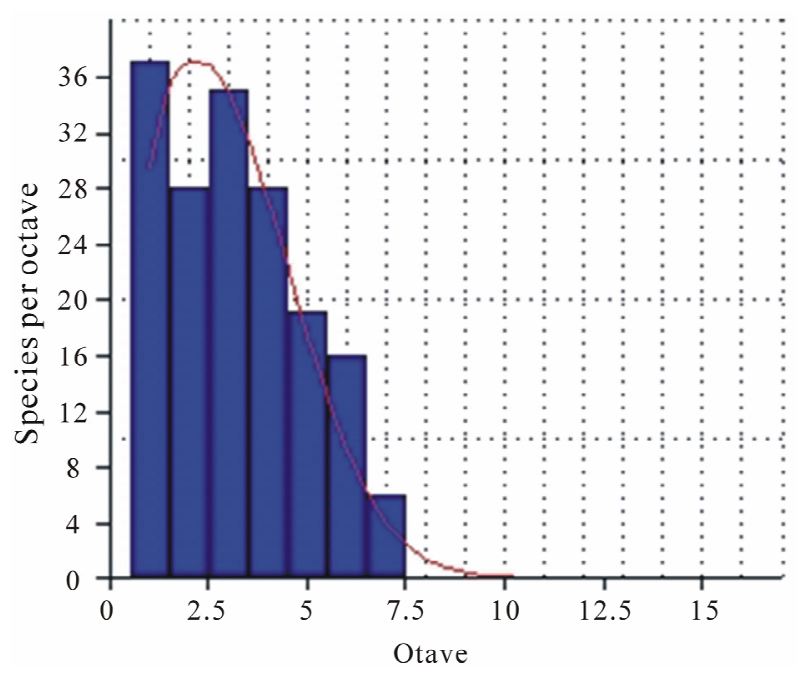

Figure 2. Frequency distribution of numbers of species per octave (p: 0.27) in 262 Winkler's samples collected in Bodoquena Mountain Range National Park. Mato Grosso do Sul State/Brazil.

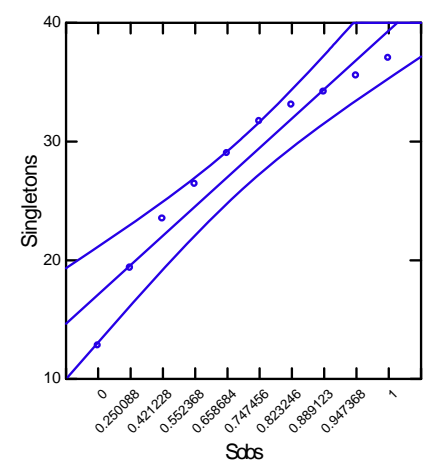

(a)

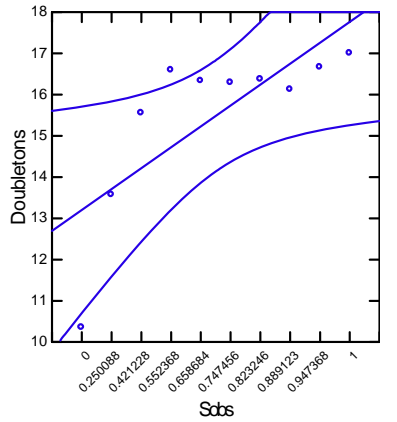

(a)

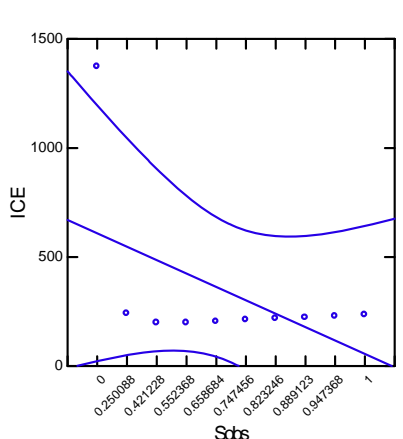

(c)
Figure 3. Pearson's correlation with datasets adjusted $(\mathrm{p}=0.5$ and $\mathrm{CI}=95 \%$ ). (a) Strong positive correlation between Sobs and Singletons; (b) Strong positive correlation between Sobs and Doubletons; (c) Moderate negative correlation between Sobs and ICE estimator. 
tive correlation between ICE estimator values with singletons $(\mathrm{R}=-0.691)$ and doubletons $(\mathrm{R}=-0.889)$ for all study sites.

The averages of species richness for each sampled site (Table 2, Figure 4) kept a constant profile for leaf-litter

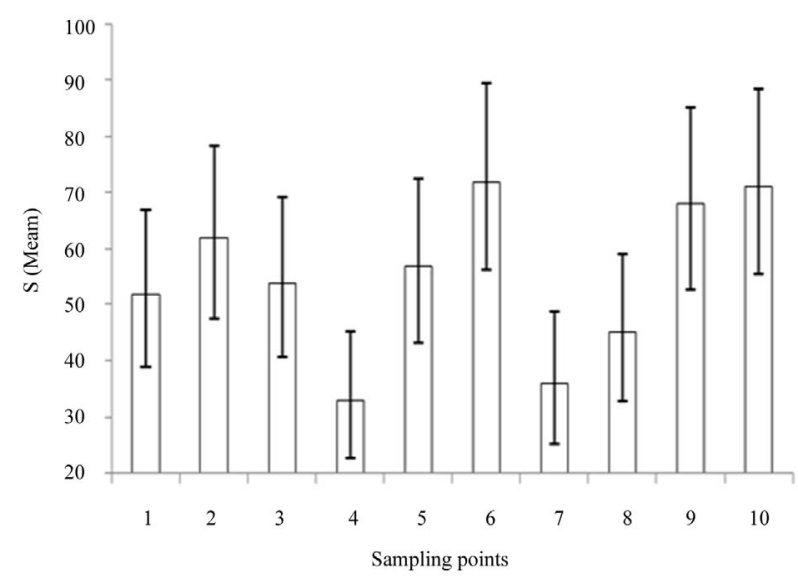

Figure 4. Minimum and maximum averages of ants species richness in 10 localities along Bodoquena range mountain, Brazil. The number of Winkler's sample for each localitie was as follow: Site 1: 25 samples, Site 2: 32, Site 3: 25 , Site 4:25, Site 5: 25 , Site 6: 25 Site 7:25, Site 8: 25 , Site 9: 30 , Site 10: 25 .

Table 1. Pearson's correlation values for 262 Winkler's samples on 10 localities at the Bodoquena range mountain National Park, Brazil.

\begin{tabular}{ccccc}
\hline \multicolumn{5}{c}{ Pearson Correlation Matrix } \\
\hline & Sobs & ICE & Singletons & Doubletons \\
\hline Sobs & 1.000 & & & \\
ICE & -0.674 & 1.000 & & \\
Singletons & 0.999 & -0.691 & 1.000 & \\
Doubletons & 0.881 & -0.889 & 0.891 & 1.000 \\
\hline
\end{tabular}

Table 2. Averages, Standard Deviation (sd) and Percentiles $\left(\mathrm{P}_{2,5 \%}\right.$ and $\left.\mathrm{P}_{97 \%}\right)$ of a Posteriori distribution with values of Species richness of 10 sampling sites through Bodoquena range mountain National Park, Brazil.

\begin{tabular}{lcccccccc}
\hline Mean & Sd & MC error Val2.5pc & Median & Val97.5pc & Start & Sample \\
\hline $\mathrm{m}[1]$ & 52 & 7.2 & 0.02372 & 38.82 & 51.67 & 67.03 & 1000 \\
$\mathrm{~m}[2]$ & 61.99 & 7.866 & 0.02501 & 47.58 & 61.66 & 78.31 & 1000 \\
$\mathrm{~m}[3]$ & 54.01 & 7.361 & 0.02324 & 40.56 & 53.69 & 69.28 & 1000 \\
$\mathrm{~m}[4]$ & 33.01 & 5.72 & 0.01838 & 22.75 & 32.7 & 45.18 & 1000 \\
$\mathrm{~m}[5]$ & 56.97 & 7.502 & 0.0249 & 43.18 & 56.66 & 72.51 & 1000 \\
$\mathrm{~m}[6]$ & 71.91 & 8.453 & 0.02748 & 56.26 & 71.58 & 89.41 & 1000 \\
$\mathrm{~m}[7]$ & 35.97 & 5.971 & 0.01824 & 25.23 & 35.62 & 48.67 & 1000 \\
$\mathrm{~m}[8]$ & 45.01 & 6.693 & 0.02167 & 32.86 & 44.68 & 59.06 & 1000 \\
$\mathrm{~m}[9]$ & 67.97 & 8.276 & 0.02499 & 52.7 & 67.62 & 85.21 & 1000 \\
$\mathrm{~m}[10]$ & 71 & 8.403 & 0.02772 & 55.42 & 70.65 & 88.41 & 1000 \\
\hline
\end{tabular}

ants. Bayesian inference analysis showed no autocorrelation between species richness and latitudinal and longitudinal gradients for ten sites sampled in dry forest from Bodoquena range mountain (Figure 5).

\section{DISCUSSION}

The relationship between sample size and estimated species richness resulted in part because the number of rare species (low frequency of occurrence) did not necessarily decrease with the increases of the sample size in this spectrum of samples. Richness estimates are highly influenced by species with low frequencies of records. This fact reflects a complex pattern of distribution on the leaf-litter ant fauna for the sites is observed. In the most preserved forest sites, this faunistic segment harbors a high number of specific ant species assemblages that nest and explore the litter by diversified forms. In general, this rare syndrome could be explained by the following ways: 1) microhabitat specificity, 2) many localized populations with geographic restriction, 3) species with small population range size, 4) a high number of species in specific guilds, and 5) the forest land cover fragmentation (Figure 1) that causes a strong selective

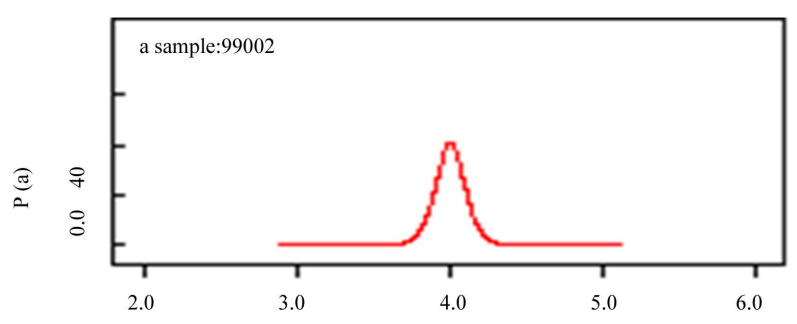

(a)

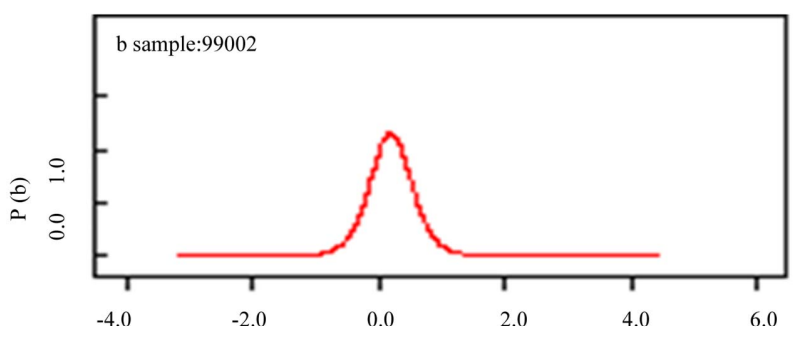

(b)

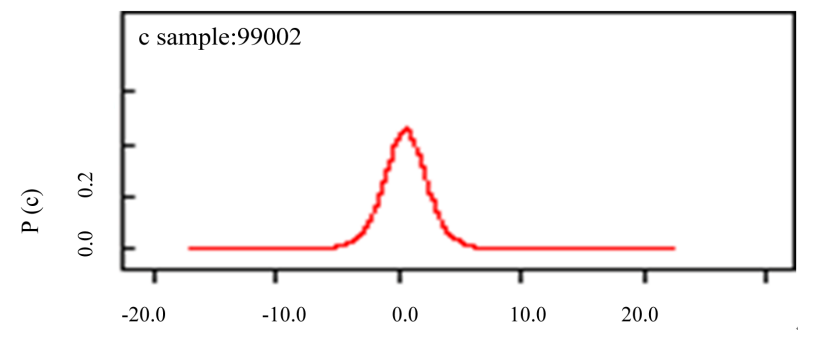

(c)

Figure 5. Bayesian inference for autocorrelation parameters with species richness (a); latitude (b) and longitude (c). The model is on the appendix 01 . 
pressure and induces a chaotic effect of vicariance. One of this driving force is explained by niche differentiation, where micro-habitats modeling action of the cryptic ant species, and many unpredictable filters can be acted.

We consider richness among samples of the most appropriate parameter for understanding local species richness and the boundaries from local to regional scale. We infer that these dynamics are given by autocorrelation between species richness and geographical gradients, or else, the transition from local to regional diversity presupposes that richness is not autocorrelated with latitudinal and longitudinal patterns, considering the phytophisionomic matrix.

The abundance and distribution of each species are determined by combinations of many historical, physical and biotic factors, and that spatial variation in population density reflects the probability density distribution of the required combinations of these variables. We argue that on the litter strata, some sets of environmental variables are distributed independently of each other, and environmental variation isn't spatially autocorrelated.

Characteristics of leaf-litter environment present a highly diverse ecological community with a small number of "common" species [39]; and other ant assemblages such as subterraneous species activity could propitiate the increase of singletons and doubletons. Studies realized by Silvestre et al. [40] and Silva \& Silvestre [41] show that the subterraneous ant species overlap activities between subterraneous layer and the upper layer, exploring the complex litter resources. The heterogenic factors such as light incidence, diversity of resources and nesting sites, amounted with an environment preserved propitiates an installation capacity of several species inside of specific guilds [42]. The regional geographic gradient showed that there was no autocorrelation with species richness for the sites sampled along Bodoquena range mountain. We verified in previous study [21] that in 100 leaf-litter samples the similarities between the samples have low values, going to $46 \%$ for unities with biggest similarities and some cases with $0 \%$ of similarities among the total of analyzed samples. Most of the similarities were driven by species inside of generalists guilds. We conclude that in a continuous forest cover, it is impossible to define a scale of alpha diversity for Formicidae, this is only possible on islands that the usual metrics of alpha e beta diversity do not apply to this model in Neotropical region [43].

We must investigate if the frequency of species substitution on each guild follows this profile and if these patterns of rarity could be compared with others localities through Neotropical region for a macro scale, considering different biomes.

\section{ACKNOWLEDGEMENTS}

We special thank ICMBio for collection authorization, Dr. Bruno
Spacek for help and suggestions in Bayesian model, and Fabrício Baccaro for critical review of the manuscript.

\section{REFERENCES}

[1] Preston, F.W. (1948) The commonness and rarity of species. Ecology, 29, 254-283. doi:10.2307/1930989

[2] Preston, F.W. (1962) The canonical distribution of commonness and rarity: Part I. Ecology, 43, 185-215. doi:10.2307/1931976

[3] Harte, J., Kinzig, A.P. and Green, J. (1999) Self-similarity in the distribution and abundance of species. Science, 284, 334-336. doi:10.1126/science.284.5412.334

[4] Hubbell, S.P. (2001) The unified neutral theory of biodiversity and biogeography. Princeton University, Princeton, 448.

[5] Gaston, K.J. (1993) Rarity. Chapman \& Hall, London.

[6] Gaston, K.J., Blackburn, T.M. and Lawton, J.H. (1996) Interspecific abundance-range size relationships: An appraisal of mechanisms. Journal of Animal Ecology, 66, 579-601. doi:10.2307/5951

[7] Andersen, A.N. (2008) Not enough niches: Non-equilibrial processes promoting species coexistence in diverse ant communities. Austral Ecology, 33, 211-220. doi:10.1111/j.1442-9993.2007.01810.x

[8] Cushman, J.H., Lawton, J.H. and Manly, B.F.J. (1993) Latitudinal patterns in European ant assemblages: Variation in species richness and body size. Oecologia, 95, 3037.

[9] Rahbek, C. (1995) The elevational gradient of species richness: A uniform pattern? Ecography, 18, 200-205. doi:10.1111/j.1600-0587.1995.tb00341.x

[10] Lomolino, M.V. (2001) Elevation gradients of speciesdensity: Historical and prospective views. Global Ecology and Biogeography, 10, 3-13. doi:10.1046/j.1466-822x.2001.00229.x

[11] Sanders, N.J. (2002). Elevational gradients in ant species richness: Area, geometry, and Rapoport's rule. Ecography, 25, 25-32. doi:10.1034/j.1600-0587.2002.250104.x

[12] Yoccoz, N.G., Nichols, J.D. and Boulinier, J.D. (2001) Monitoring of biological diversity in space and time. Trends in Ecology \& Evolution, 16, 446-453.

[13] Kaspari, M. and Weiser, M. (1999) The size-grain hypothesis and interspecific scaling in ants. Functional Ecology, 13, 530-538. doi:10.1046/j.1365-2435.1999.00343.x

[14] Barrow, L., Parr, C.L. and Kohen, J.L. (2006) Biogeography and diversity of ants in Purnululu (Bungle Bungle) National Park and Conservation Reserve, Western Australia. Australian Journal of Zoology, 54, 123-136. doi:10.1071/ZO06009

[15] Byrne, M.M. (1994) Ecology of twig-dwelling ants in a wet lowland tropical Forest. Biotropica, 26, 61-72. doi:10.2307/2389111

[16] Agosti, D. and Alonso, L.E. (2000) The ALL protocol: A standard protocol for the collection of ground-dwelling ants. In: Agosti, D., Majer, J.D., Alonso, L.E. and Schultz, T. (Eds.), Ants: Standard Methods for Measuring and Mo- 
nitoring Biodiversity, Smithsonian Institution Press, Washington DC, 204-206.

[17] Silva, R.R. and Silvestre, R. (2000) Diversidade de formigas (Hymenoptera: Formicidae) em Seara, Oeste de Santa Catarina. Biotemas, 13, 85-105.

[18] Delsinne, T., Leponce, M., Theunis, L., Braet, Y. and Roisin, Y. (2008) Rainfall influences ant sampling in dry forests. Biotropica, 40, 590-596. doi:10.1111/j.1744-7429.2008.00414.x

[19] Silva, R.R., Feitosa, R.S.M. and Eberhardt, F. (2007) Reduced ant diversity along a habitat regeneration gradient in the southern Brazilian Atlantic Forest. Forest Ecology and Management, 240, 61-69. doi:10.1016/j.foreco.2006.12.002

[20] Lessard, J.P., Robert, R., Dunn, R.R., Charles, R., Parker, C.R. and Sanders, N.J. (2007) Rarity and diversity in forest ant assemblages of Great Smoky Mountains national park. Southeastern Naturalist, 1, 215-228. doi:10.1656/1528-7092(2007)6[215:RADIFA]2.0.CO;2

[21] Silvestre, R., Demétrio, M.F. and Delabie, J.H.C. (2012) Community structure of leaf-litter ants in a neotropical dry forest: A biogeographic approach to explain betadiversity. Psyche, 2012, 1-15. doi:10.1155/2012/306925

[22] Schoener, T.W. (1971) Theory of feeding strategies. Annual Review of Ecology and Systematics, 2, 369-404. doi:10.1146/annurev.es.02.110171.002101

[23] Kaspari, M. (1996) Litter ant patchiness at the 1-m2 scale: Disturbance dynamics in three Neotropical forests. Oecologia, 107, 265-273. doi:10.1007/BF00327911

[24] Delabie, J.H.C., Agosti, D. and Nascimento, I.C. (2000) Litter ant communities of the Brazilian Atlantic Rain Forest Region. School of Environmental Biology, 18, 117.

[25] Silva, R.R. and Silvestre, R. (2004) Riqueza da fauna de formigas (Hymenoptera: Formicidae) que habita as camadas superficiais do solo em Seara, Santa Catarina. $\mathrm{Pa}$ peis Avulsos de Zoologia, 44, 1-11. doi:10.1590/S0031-10492004000100001

[26] Lawton, J.H. (1995) Population dynamic principles. In: Lawton, J.H. and May, R.M. (Eds.), Extinction Rates, New York, Oxford University Press Inc.

[27] Lassau, S.A. and Hochuli, D.F. (2004) Effects of habitat complexity on ant assemblages. Ecography, 27, 157-164. doi:10.1111/j.0906-7590.2004.03675.x

[28] Beck, M.W. (1997) Inference and generality in ecology: Current problems and an experimental solution. Oikos, 78, 265-273. doi: $10.2307 / 3546293$

[29] Wilson, E.O. (2000) A global biodiversity map. Science, 289, 22-79.

[30] Morrone, J.J. (2006) Biogeographic areas and transition zones of Latin America and the Caribbean islands based on panbiogeographic and cladistic analysis of the entomofauna, Annual Review of Entomology, 51, 467-494. doi:10.1146/annurev.ento.50.071803.130447

[31] Ministério do Meio Ambiente, Brasil (2007) Biodiver- sidade Brasileira: Avaliação e identificação de ações prioritárias para a conservação, utilização sustentável e repartição dos benefícios da biodiversidade brasileira. Brasília, MMA, Secretaria de Biodiversidade e Florestas. http://www.mma.gov.br

[32] Agosti, D., Majer, J., Alonso, E. and Schultz, T.R. (2000) Ants: Standard methods for measuring and monitoring biodiversity. Smithsonian Institution Press, Washington DC.

[33] Colwell, R.K. (2004) Estimates: Statistical estimation of species richness and shared species from samples, Version 8.0 b1, User's Guide and application.

[34] Colwell, R.K., Mao, C.X. and Chang, J. (2004) Interpolating, extrapolating, and comparing incidence-based species accumulation curves. Ecology, 85, 2717-2727. doi:10.1890/03-0557

[35] Chazdon, R.L., Colwell, R.K., Denslow, J.S. and Guariguata, M.R. (1998) Statistical methods for estimating species richness of woody regeneration in primary and secondary rain forests of NE Costa Rica. In: Dallmeier, F. and Comiskey, J.A. (Eds.), Forest Biodiversity Research, Monitoring and Modeling: Conceptual Background and Old World Case Studies, Parthenon Publishing, Paris.

[36] Longino, J. T., Coddington, J. and Colwell, R.K. (2002) The ant fauna of a tropical rain forest: Estimating species richness three different ways. Ecology, 83, 689-702.

[37] Systat (2007) Systat software for Windows, Version 12.

[38] Spiegelhalter, D., Thomas, A., Best, N. and Lunn, D. (2010) WinBUGS User Manual Version 3.1.2. MRC Biostatistics Unit, Cambridge.

[39] Pitman, N.C.A., Terborgh, J.W. and Silman, M.R. (2001) Dominance and distribution of tree species in upper Amazonian Terra Firme forests. Ecology, 82, 2101-2017. doi:10.1890/0012-9658(2001)082[2101:DADOTS]2.0.C $\underline{\mathrm{O} ; 2}$

[40] Silvestre, R., Brandão, C.R.F. and Silva, R.R. (2003) Grupos funcionales de hormigas: El caso de los grêmios del Cerrado, Brasil. In: Fernández, F. (Ed.), Introdución a las hormigas de la región Neotropical, Instituto Humboldt, Bogotá, 113-143.

[41] Silva, R.R. and Silvestre, R. (2004) Riqueza da fauna de formigas (Hymenoptera: Formicidae) que habita as camadas superficiais do solo em Seara, Santa Catarina. Papeis Avulsos de Zoologia, 44, 1-11. doi:10.1590/S0031-10492004000100001

[42] Wiens, J.J., Graham, C.H., Moen, D.S., Smith, S.A. and Reeder, T.W. (2006) Evolutionary and ecological causes of the latitudinal diversity gradient in hylid frogs: Tree frog trees unearth the roots of high tropical diversity. The American Naturalist, 168, 579-595. doi:10.1086/507882

[43] Gering, J.C. and Crist, O. (2002) The alfa-beta-relationship: Providing new insights into local-regional patterns of species richness and scale dependence of diversity components. Ecology Letters, 5, 433-444. doi:10.1046/j.1461-0248.2002.00335.x 